\title{
NOTES ON SINEA DIADEMA (FABR.); HEMIPTERA
}

\author{
By Geo. W. Barber.
}

Bureau of Entomology, U. S. Dept. of Agriculture.

During the month of September the blossoms of goldenrod are visited by myriads of insects, many of which are attracted there for the food that may be obtained from the flowers. But all is not fortunate, sometimes, for the unwary fly or bee, especially when Phymata erosa (Linn.) and spiders such as $M i$ sumena vatia await them. These, by means of the color with which nature has favored them, are all but indistinguishable from the blossoms. Other predators not so fortunately endowed are frequently present on the flowers, that must for them be excellent hunting grounds. Among these is Sinea diadema (Fabr.) one of the most common species of the Reduviidæ, which though not of particularly ferocious appearance to our eyes, must seem sufficiently so to the insect that it attacks.

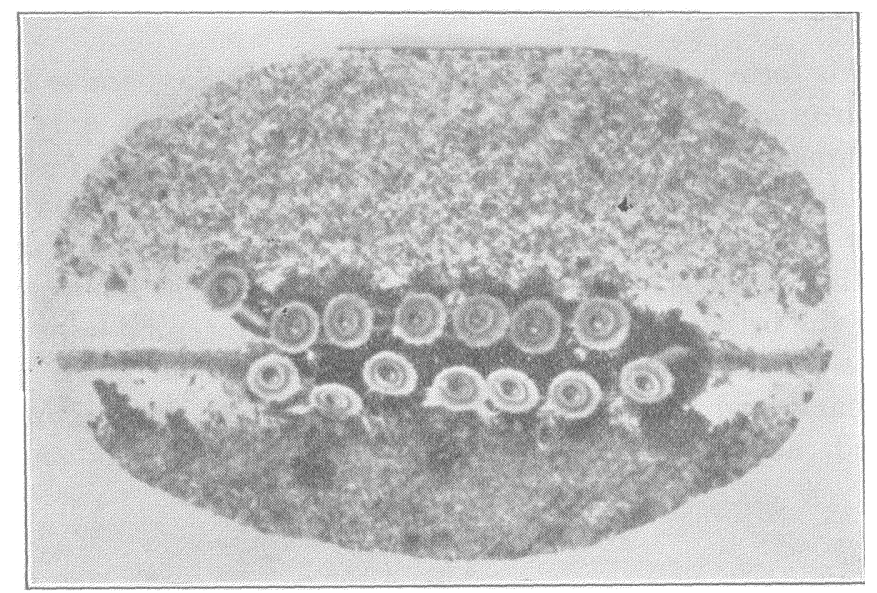

Fig. 1. Sinea diadema (Fabr.) Egg-mass enlarged six diameters.

Eggs of this species may be readily obtained by confining the adults in salve boxes. They are deposited usually in small 
masses, the individual eggs upright and arranged in two rows. As thus seen under magnification they are very beautiful, the structures of the cap and the collar-like extension of the chorion, which extends outwards from the new laid egg, appearing like delicate lace.

The first instar nymph is a most grotesque little insect with a very large head powerful beak and large, strong front femora provided with numerous stout, sharp spines. The armature is admirably designed for a predatory habit, the head and thorax being covered with plates of very stout, smooth, black chitin against which, we are pleased to believe, a much larger insect might struggle without effect, once it is in the grasp of powerful front femora. Young nymphs that I confined wasted no time on covering themselves with litter and soon became all but indistinguishable. Here again the insect is found superbly fitted for its habit, for on the thorax it bears four sharp, stout spines, than which no structure, perhaps, would better serve for retaining the litter with which it covers itself.

The egg of this species has been described by Ashmead (1895-Insect Life VII p. 321) and Heideman (1911-Proc. Ent. Soc. Wash. XIII p. 135) and the young nymph by Ashmead. Since I intend to display illustrations, I have enlarged these excellent descriptions somewhat.

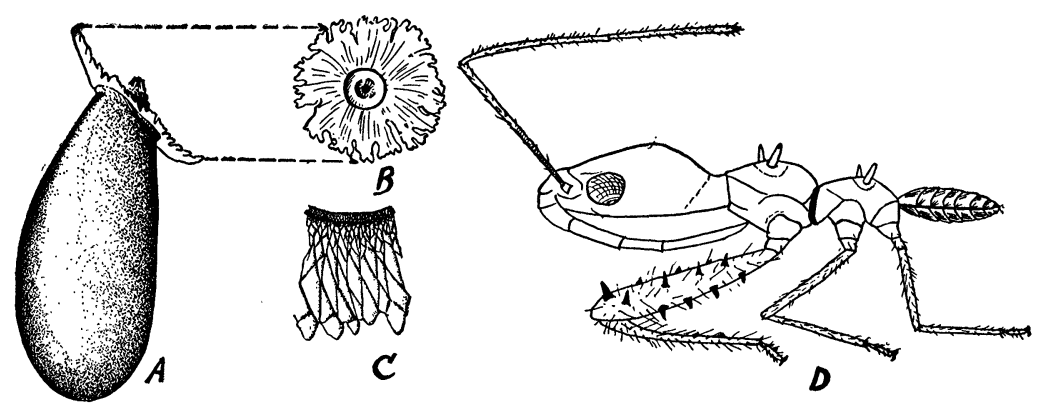

Fig. 2. Sinea diadema (Fabr.) A-egg, lateral view; B-egg, dorsal view of the cap and the extension of the chorion; C-Detail structure of the extension of the chorion; $\mathrm{D}$-first instar nymph, lateral view; E-egg mass.

Egg. Length $1.3 \mathrm{~mm}$.; width $.6 \mathrm{~mm}$; diameter of extension of chorion $.8 \mathrm{~mm}$. Color brown, minutely granulated, somewhat 
shining; central area of cap brown, outer rim brown with minute, regular, white reticulations; extension of the chorion white with dark lines, brown towards the inner edge; shape, subilliptical, narrowed towards the cap; central area of the cap raised, cone-like, bluntly rounded at the tip, composed of several scales which fail to meet at the tip; outer rim of the cap flat with minute, regular reticulations; extension of the chorion on the same plane with the outer rim of the cap in new laid eggs, after hatching or drying bending upwards or downwards, squamose, minutely so towards the inner border, gradually coarser outwards, edge sinuate; chorial processes numerous, elongate, club-shaped, within the extension of the chorion.

First Instar Nymph. Length $1.8 \mathrm{~mm}$; Color dark brown to black, the antennæ, except the basal half of the first segment, the apical half of the middle and posterior tibiæ and all the tarsi brownish; eyes red; body smooth, shining, plates of the head and thorax strong and heavy, closely united; head oblong, as long as the thorax, wider and elevated behind the eyes, then depressed and narrowing into a neck of moderate length; antennæ cylindrical, 4-jointed, as long as or slightly longer than the body, first and last joints subequal, second and third united less than the first, minutely and sparsely ciliate, the basal joint less so, hairs light brown; beak very stout at base, gradually narrowing, attaining the front coxæ; pro and mesothorax each provided with a stout spine each side the median line, as long as one fourth the length of the prothorax and separated by about their own length, directed upwards; anterior legs with very stout femora, enlarged towards the apex, with several stout, sharp spines arranged in rows, those towards the apex larger, each with a hair arising from the apex, sparsely pilose, the hairs long; tibiæ slender with three blunt spines beneath, more densely pilose than the femora; middle and posterior legs somewhat shorter and more slender, moderately pilose; abdomen short, somewhat more than half the length of the thorax, rounded, somewhat flattened, the edges moderately undulated and sparsely fringed with tufts of hairs. 

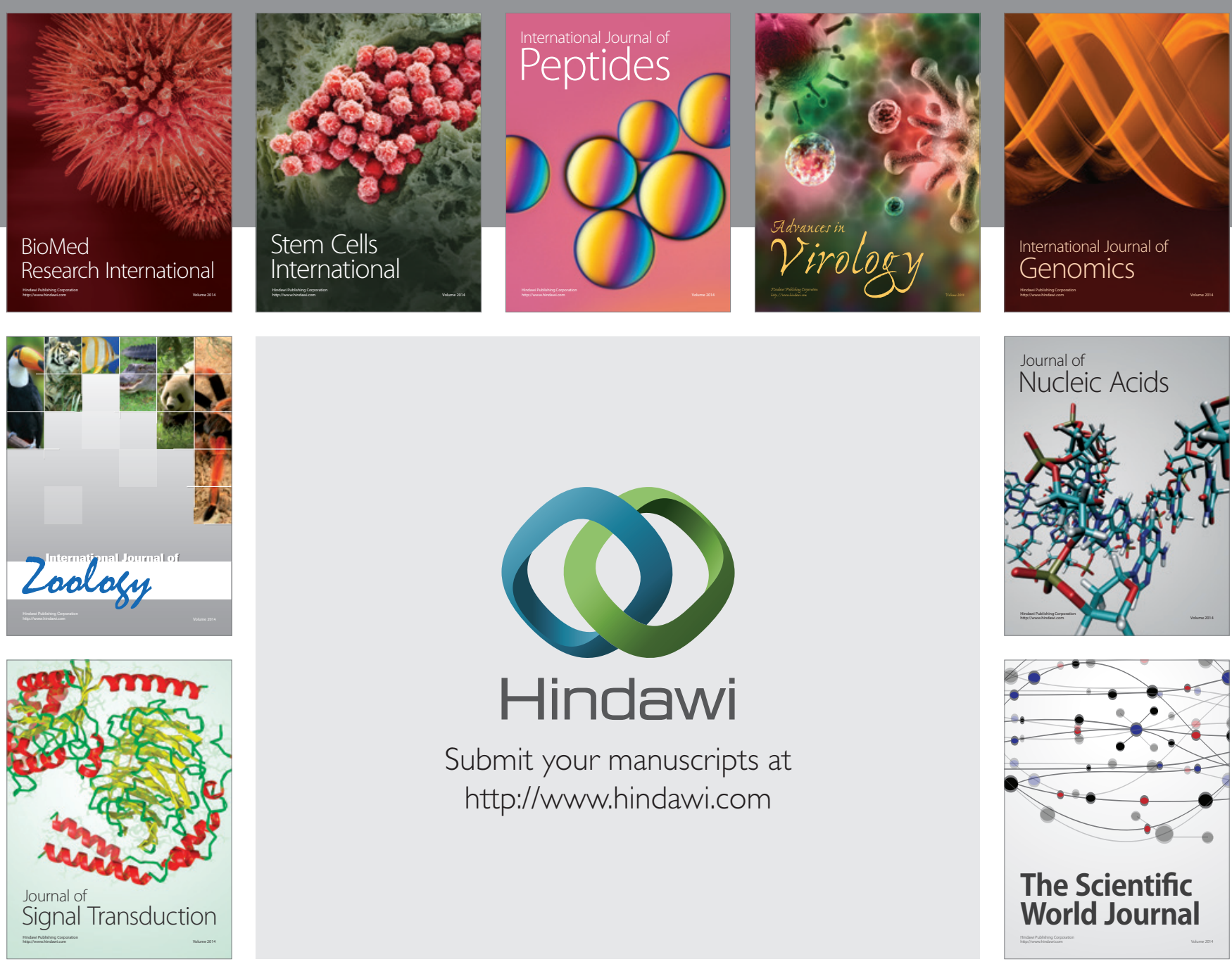

Submit your manuscripts at

http://www.hindawi.com
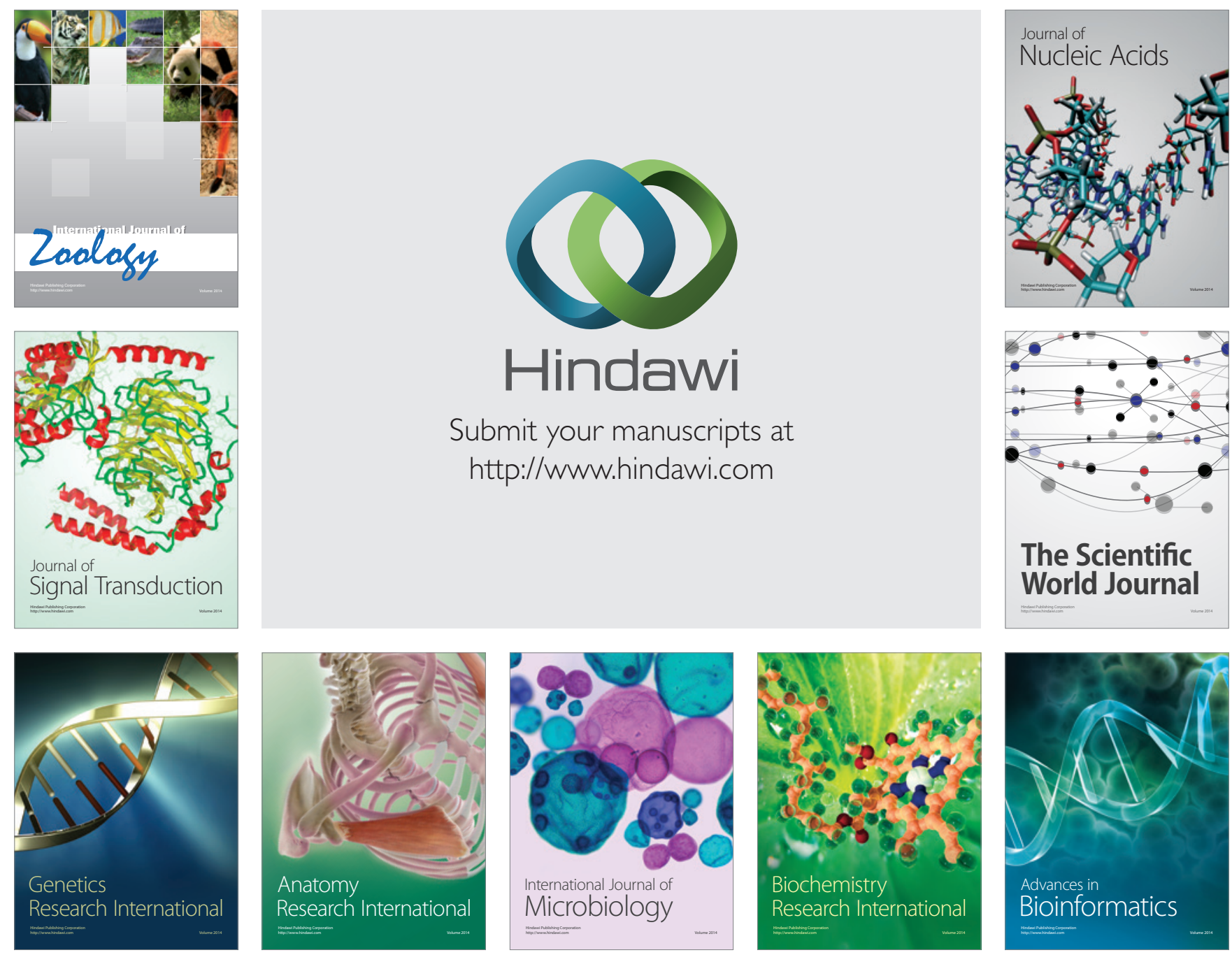

The Scientific World Journal
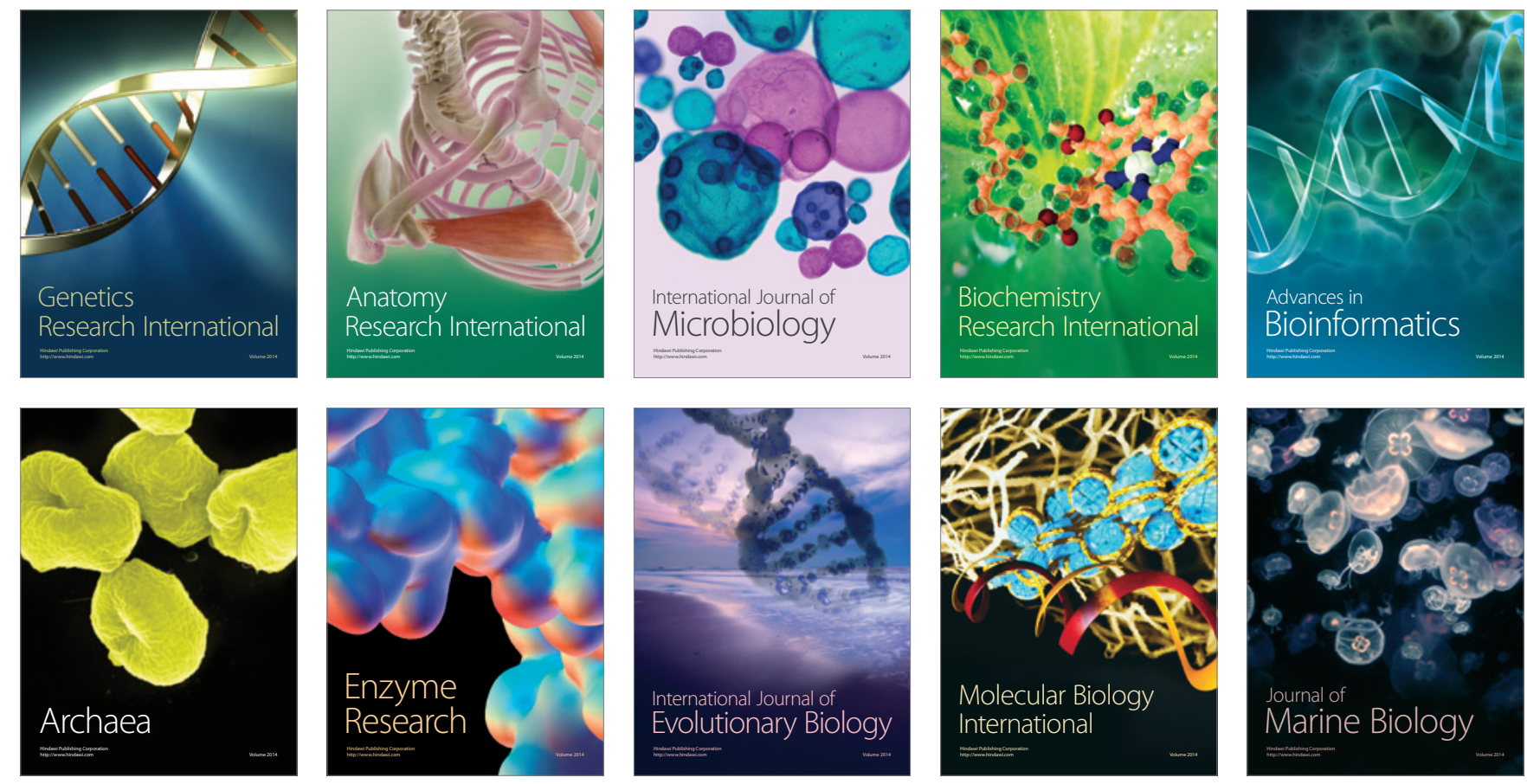